\title{
18-pulse rectifier in arrangement with coupled three-phase reactor
}

\author{
J. Iwaszkiewicz ${ }^{1}$, A. Muc ${ }^{1}$ and P. Mysiak ${ }^{1}$ \\ ${ }^{1}$ Department of Electrical Engineering \\ Gdynia Maritime University, Poland \\ Morska St. 81-87 (Poland) \\ e-mail: j.iwaszkiewicz@we.umg.edu.pl, a.muc@we.umg.edu.pl, p.mysiak@we.umg.edu.pl
}

\begin{abstract}
The paper presents a proposal of a developed multipulse AC/DC converter built from three 6-pulse bridge rectifiers. These rectifiers are connected in parallel to form an 18-pulse rectifier. The converter is connected to the line by use of coupled reactors working in an specialized circuit. The converter is convenient for supplying high power devices e.g. multilevel inverters and gives a very good performance. Simulation and experimental works prove the usefulness of the converter as well as its respectable properties.
\end{abstract}

\section{Key words}

Multi-pulse rectifier, 18-pulse rectifier, coupled reactors.

\section{Introduction}

Providing supply for electrical energy conversion systems in which multilevel inverters are used brings serious problems related to the high load volume. The supply network is powerfully overloaded what provokes numerous compatibility problems. Contemporary converters are designed using very fast switching semiconductor connectors and are used in situations when large power as well as high power quality are required at the reception side $[1,2,3,4]$.

A multilevel voltage inverter requires a multipolar DC voltage supply in which the number of poles corresponds to the number of levels in the inverter. For instance, in the three-level voltage inverter of NPC type, the internal inverter system should be capable of being connected to three poles of the supply network. In standard NPC inverters, a common procedure is to use for this purpose an intermediate circuit with divided voltage $U_{D}$, the three poles of which correspond to potentials $0, U_{D} / 2$, and $U_{D}$. The voltage to the intermediate circuit is usually delivered by $\mathrm{AC} / \mathrm{DC}$ voltage rectifiers. They are nonlinear receivers of electrical energy thus generating higher harmonics in the supply network. These harmonics are highly undesirable, since they are a source of additional power losses in the supply line, deform the supply voltage, and emit electromagnetic signals which disturb the operation of IT and control systems. The international standards, IEEE for instance, define very severe requirements concerning the presence of higher harmonics in the currents taken from the supply sources and the permissible voltage distortion[5]. The standards describe acceptable values of $\mathrm{THD}_{\mathrm{I}}$ and $\mathrm{THD}_{\mathrm{U}}$ factors usually used in power electronics. They define current and voltage distortion. The permissible voltage distortion coefficient for receivers supplied from the NN network is equal to $3 \%$ in the case of special objects, such as hospitals or airports for instance, and to $5 \%$ for general objects including industrial plants. In general, the permissible current distortion coefficient should not exceed several percent $(2 \% \div 10 \%)$. It is also noteworthy here that the requirements referring to permissible amplitudes of individual current harmonics are also standardised.

A multi-pulse AC/DC converter generates current harmonics, the order of which depends on $\mathrm{q}$.

$$
h=k q \pm 1 \quad k \in \mathrm{N}
$$

If the converter works together with an ideal inductive filter, which ensures a pulse less waveform of the stabilised current (zero ripple current), and is additionally supplied from an ideal voltage source, then the following relation is satisfied:

$$
I_{h}=\frac{I_{1}}{h}
$$

An obvious conclusion resulting from formulas (1) and (2) is that we should use converter systems with large $\mathrm{q}$ values (multi-pulse systems) to meet the requirements defined by the standards. In practice 6-, 12-, and 18-pulse systems are frequently used for supplying inverters in AC drives. In classical solutions, the $q$ value can be multiplied, for instance, by serial and parallel connection of three-phase bridge systems and relevant phase shift in the transformers supplying the converters. The paper presents a proposal of rectifier supplying a three-level inverter with the DC voltage obtained from the AC/DC converter in which multi-pulse diode rectifiers with coupled reactors were applied to block higher current harmonics. 


\section{Multi-pulse AC/DC converter with coupled reactors}

The supply for the intermediate circuit of the three-level voltage inverter could be provided by a multi-pulse AC/DC converter with coupled reactors. Good properties of the supply system are ensured by connecting together three three-phase bridge rectifiers which deliver, respectively, the stabilised voltage to the intermediate circuit. Introducing coupled reactors to the converters improves the compatibility of the system. The 18-pulse rectifier is presented in this Chapter.

The application of the 3CR $\lambda$ system for parallel connection of three three-phase diode bridge rectifiers is presented in Fig. 1 [6, 7, 8, 9]. The figure shows a scheme of the 18-pulse diode rectifier with parallel operation of three three-phase bridge converters, working at capacitiveinductive load which simulates the intermediate circuit of a 3 -level inverter. The three-phase supply network is represented by the source voltages $\mathrm{E}_{\mathrm{k}}(\mathrm{k}=\mathrm{a}, \mathrm{b}, \mathrm{c})$ and the line inductance $\mathrm{L}_{\mathrm{w}}$. Moreover, reactors with inductance $\mathrm{L}$ are installed in series with the supply source. The task of these reactors is to reduce higher harmonics of currents taken by the rectifier from the network. The parallel operation of three three-phase bridge rectifiers whose voltages are phase shifted by $20^{\circ}$ is executed using two coupled three-phase reactors: the current divider WPP and the $3 \mathrm{CR} \lambda$ system, which execute the phase shift by $40^{\circ}$ for two sets of three-phase voltage. load (voltage $\mathrm{U}_{\mathrm{Kn}-\mathrm{N}}$ ). The 18-pulse time-histories of phase voltages are obtained under the assumption that the conduction angles of the rectifier diodes are equal to $\pi$. The voltages $\mathrm{U}_{\mathrm{Ka}-\mathrm{N}}$ measured between terminals $\mathrm{K}_{\mathrm{a}}$ and the neutral point $\mathrm{N}$ can be interpreted as the quantities appearing as a result of cyclic switching, via diodes, of three DC voltage bridges $2 \mathrm{E}_{\mathrm{d}}$. The 18-pulse timehistories of voltages $\mathrm{U}_{\mathrm{Kn}-\mathrm{N}}$ are obtained only when the diode conduction angles in individual rectifiers are equal to Mand the conduction intervals (18 intervals) are distributed symmetrically along the supply voltage period. In this case, each three-phase bridge rectifier generates a voltage system with 6-stage waveform on AC terminals. The phase voltages measured on terminals $\mathrm{D}_{1}$ with respect to the neutral point precede by $20^{\circ}$ the corresponding phase voltages measured on terminals $\mathrm{D}_{2}$. In turn, the phase voltages measured on terminals $\mathrm{D}_{3}$ are phase delayed by $20^{\circ}$ with respect to the corresponding phase voltages measured on terminals $\mathrm{D}_{2}$. This way the $3 \mathrm{CR} \lambda$ system executes the $40^{\circ}$ phase shift between two output voltage systems.

The electromagnetic systems WPP and 3CR $\lambda$ make it possible to obtain the required division of the current taken from the supply source and delivered to individual bridge rectifiers. Three systems of three-phase currents which supply particular rectifiers are characterised by the same RMS value and approximately the same sinusoidal waveforms of the phase currents. Like for voltages, the currents in system $1\left(\mathrm{i}_{\mathrm{ln}}\right)$ precede by $20^{\circ}$ those in system $2\left(i_{2 n}\right)$, while the currents in system $3\left(i_{13 n}\right)$ are phase delayed by $20^{\circ}$ with respect to those in system 2 .

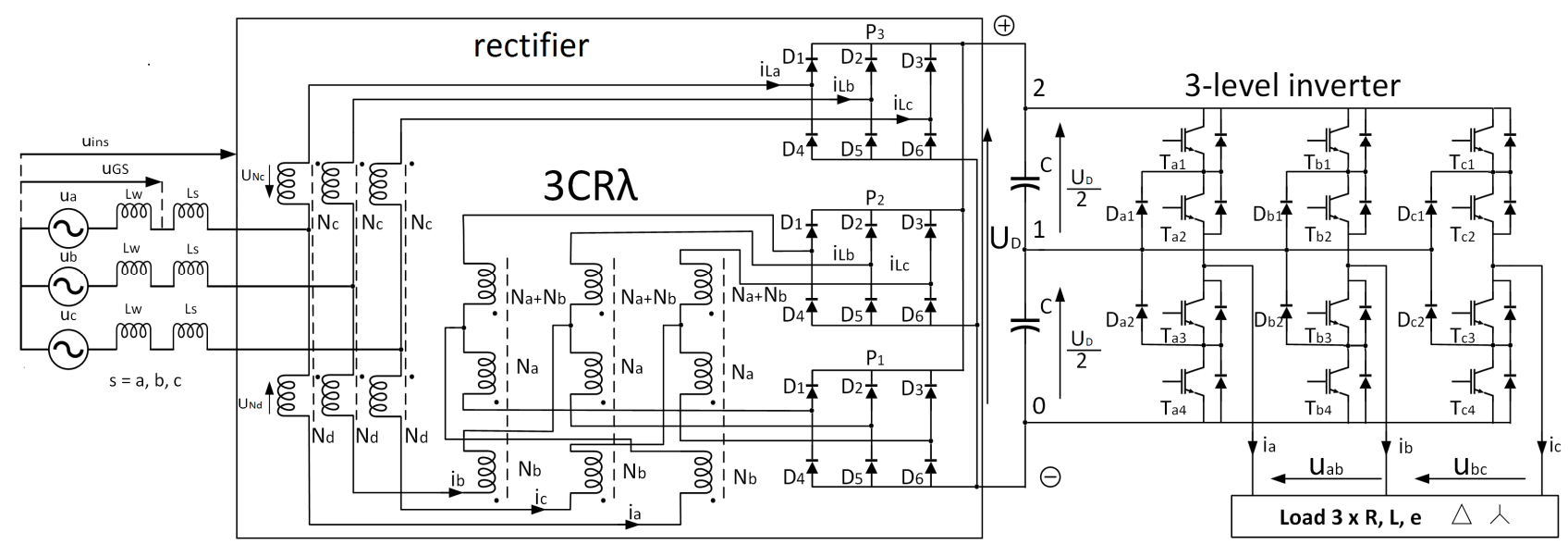

Fig. 1. Schematic diagram of the 18-pulse rectifier supplying a 3-level inverter.

The 18-pulse rectifier with a system of coupled reactors is supplied from the three-phase network having the internal inductance $\mathrm{L}_{\mathrm{w}}$ in each phase. Network reactors of inductance $\mathrm{L}_{\mathrm{s}}$, much higher than the internal inductance of the source, $\mathrm{L}_{\mathrm{s}}>>\mathrm{L}_{\mathrm{w}}$, were installed between the phase voltage and the rectifier input. The intermediary output voltage of the rectifier is divided by two in order to supply 3-level inverter. The schematic diagram of the considered converter is presented in Fig. 1.

The basic assumption in the adopted concept of the converter system is creating three spatial vectors of threephase voltages mutually shifted by $20^{\circ}$, with a sinusoidal waveform at idle and an 18-stage waveform at nominal
The effect of the operation of the coupled three-phase reactors is conversion of the three-phase voltage of the supply source into the nine-phase voltage. The reactors consist of three separate magnetic cores with relevant windings on them. The selected number of winding turns and their connections result from the required voltage phase shift (3CR $\lambda$ system)and the required preliminary current division (WPP system). Assuming the identity of flows in the WPP system, we get $\mathrm{N}_{\mathrm{D}} / \mathrm{N}_{\mathrm{C}}=\mathrm{N}_{\mathrm{B}} / \mathrm{N}_{\mathrm{A}}$. The total rated power of the reactors is equal to $16,51 \% \mathrm{P}_{\mathrm{d}}$. The THD coefficient is slightly lower than $5 \%$ (laboratory tests). 


\section{Results of simulation and experimental tests of the 18 -pulse rectifier}

The simulation tests of system operation were performed for different current values. First test have been executed assuming that the load power was constant and equal to 2 $\mathrm{kVA}$. Finally the converter work has been verified at 20 $\mathrm{kW}$ load. The 18-pluse rectifier system was built and tested in the Power Electronics Laboratory of the Gdynia Maritime University. Basic parameters of the simulation model of the rectifier system are collated in Table 1 .

Table 1. - Parameters of simulation and laboratory models of 2 kVA 18-pulse rectifier.

\begin{tabular}{|l|l|}
\hline DC Power & $\mathrm{P}_{\mathrm{d}}=20 \mathrm{~kW}$ \\
\hline Line to linevoltage & $\mathrm{U}_{\mathrm{s}}=400 \mathrm{~V}$ \\
\hline Short circuit voltage $\left(\mathrm{L}_{\mathrm{w}}+\mathrm{L}_{\mathrm{s}}\right)$ & $\mathrm{u}_{\mathrm{z} \%}=10 \%$ \\
\hline Maximal inductance in magnetic core & $\mathrm{B}_{\mathrm{m}}=1,0 \mathrm{~T}$ \\
\hline Line choke inductance & $\mathrm{L}_{\mathrm{s}}=2,2 \mathrm{mH}$ \\
\hline Load capacitor capacitance & $\mathrm{C}=10 \mathrm{mF}$ \\
\hline Load resistance & $\mathrm{R}=10,2 \Omega$ \\
\hline $\begin{array}{l}\text { Shift angle between bridge rectifiers' } \\
\text { input vectors }\end{array}$ & $2 \alpha=40^{\circ}$ \\
\hline Line internal inductance & $\mathrm{L}_{\mathrm{w}}=0,1 \mathrm{mH}$ \\
\hline Maximal magnetic permeability & $\mu_{\mathrm{Femax}}=0,044 \mathrm{H} / \mathrm{m}$ \\
\hline Coefficient of core filling with iron & $\mathrm{k}_{\mathrm{Fe}}=0,9$ \\
\hline DC Power & $\mathrm{P}_{\mathrm{d}}=20 \mathrm{~kW}$ \\
\hline Line to linevoltage & $\mathrm{U}_{\mathrm{s}}=400 \mathrm{~V}$ \\
\hline
\end{tabular}

The selected results of simulation tests are shown in Figs. 2 - 5. The voltage and current waveforms shown in those figures are compatible with the assumptions and applied theory.

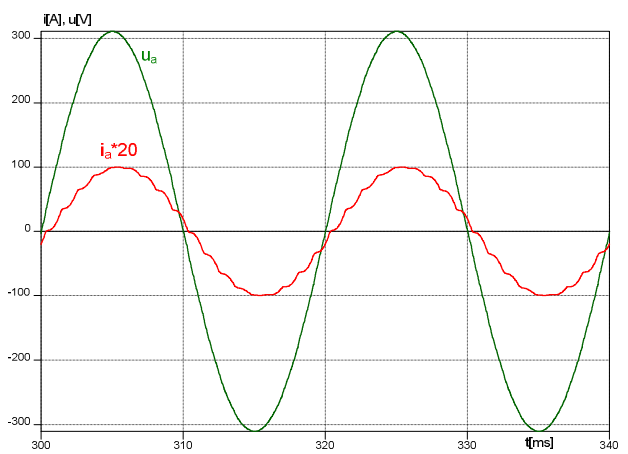

Fig. 2. Waveforms of network phase voltage $u_{a}$ and current $i_{a}$.

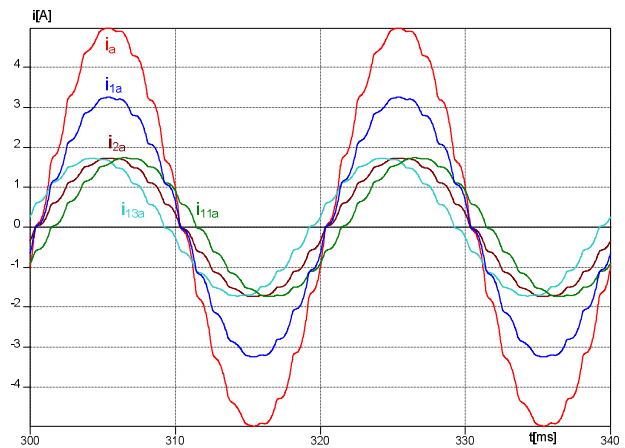

Fig. 3. Waveforms of network current $i_{a}$, currents $i_{11 a}, i_{13 a}$ in $3 \mathrm{CR} \lambda$ windings, and currents $\mathrm{i}_{2 \mathrm{a}}, \mathrm{i}_{1 \mathrm{a}}$ in WPP windings.

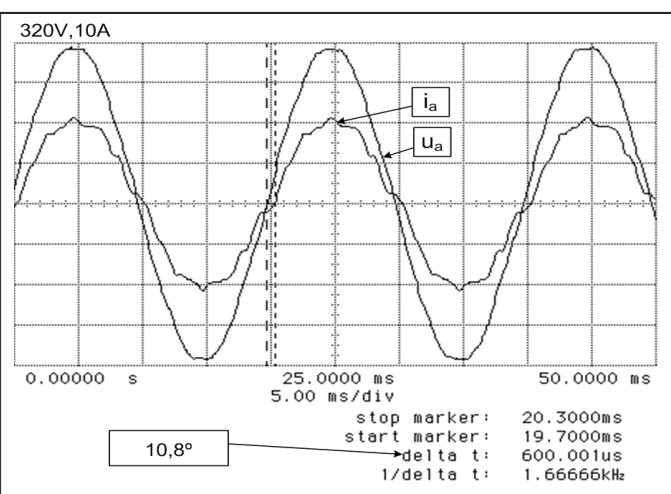

Fig. 4. Oscillograms of supply network voltage $u_{a}$ and current $i_{a}$ with measured phase shift.

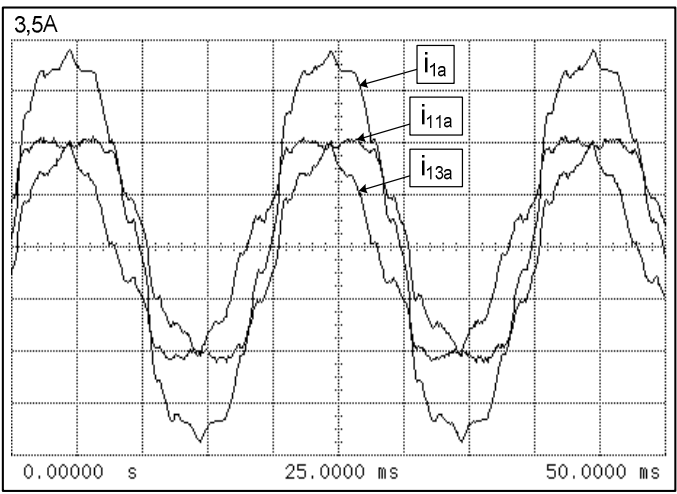

Fig. 5. Oscillograms of $3 C R \lambda$ winding currents $i_{1 a}, i_{11 a}, i_{13 a}$ at nominal converter load.

Next figures 6 and 7 present further simulation results: diode current and spectrum analysis.

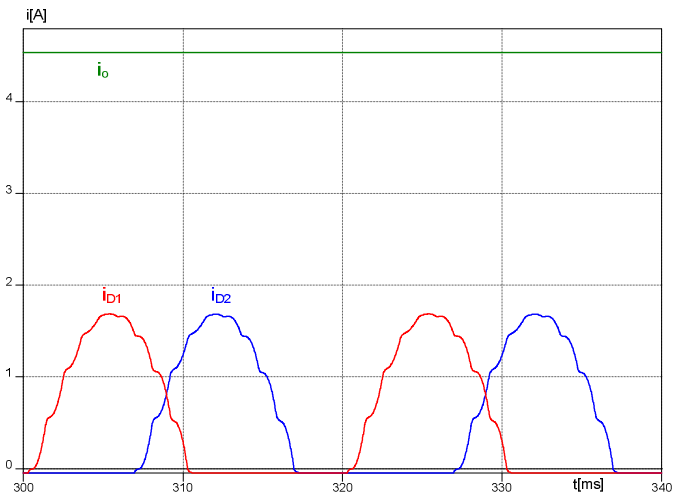

Fig. 6. Current waveforms of selected diodes D1 i D2 in the rectifier $\mathrm{P} 2$ and resulting in current of the 18 -pulse converter $\mathrm{i}_{\mathrm{o}}$.

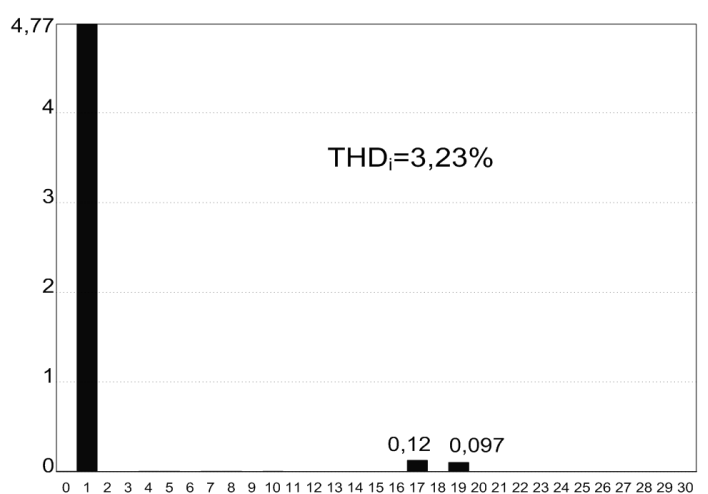

Fig. 7. Spectrum analysis of the line current. 
The shape of the line current waveform is almost equal to the mathematical sine wave. Assumed parameters effect that the shift angle between current and voltage fundamentals is very slight and teaches about $10^{\circ}\left(\cos \varphi_{1} \approx 0,985\right)$. Input voltage of the WPP circuit has a 18-stepped waveform. Input currents of rectifiers P1, P2 and P3 are mutually shifted on $20^{\circ}$. Conduction angle of diodes is approached to $180^{\circ}$. In the waveform of the line current do not practically appear harmonics of $11^{\text {th }}$ and $13^{\text {th }}$ harmonics. Harmonics 17th and 19th are strongly suppressed. The $\mathrm{THD}_{\mathrm{i}}$ factor is equal to $3,23 \%$. Further figures 8-10 confirm a very good performance of the system supplying the 3-level inverter.

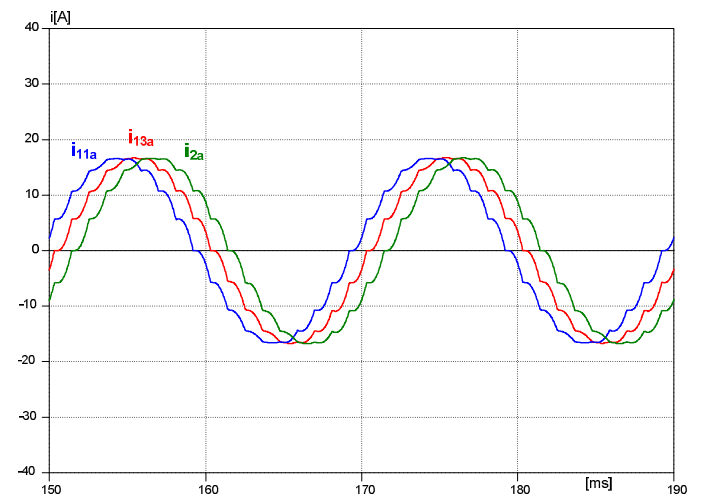

Fig. 8. Waveforms of currents $\mathrm{i}_{11 \mathrm{a}}, \mathrm{i}_{2 \mathrm{a}}, \mathrm{i}_{13 \mathrm{a}}$ supplying bridge rectifiers. The currents are phase shifted mutually-simulation tests at rating load.

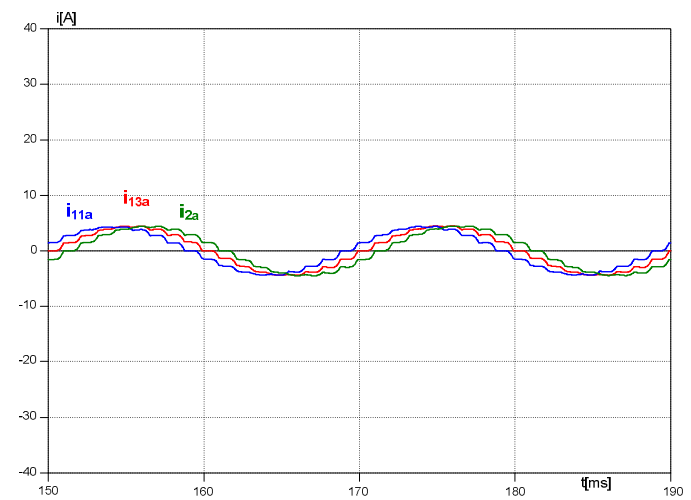

Fig. 9. Waveforms of currents $i_{11 a}, i_{2 a}, i_{13 a}$ supplying bridge rectifiers. The currents are phase shifted mutually - simulation tests at $25 \%$ of rating load.

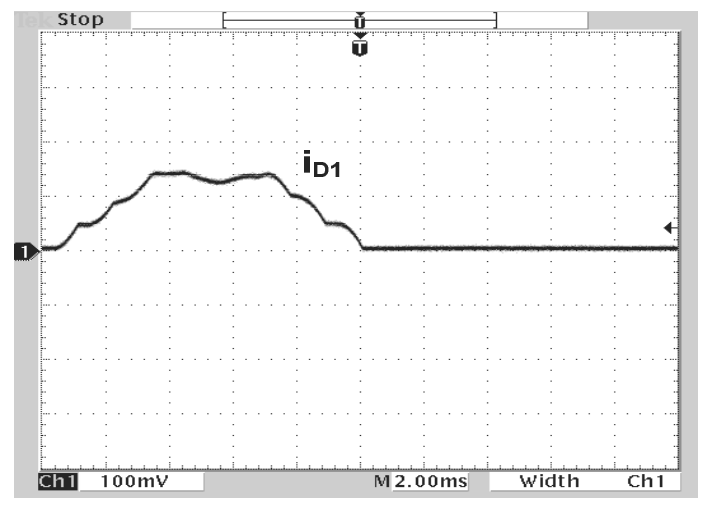

Fig. 10. Oscillogram of the diode D1 current in the bridge rectifier; the conduction angle is almost equal to $180^{\circ}$ experimental tests at rated load $20 \mathrm{~kW}$.
One can compare this diode current waveform to that one obtained during simulation tests. The relevant waveform is presented in Fig. 11.

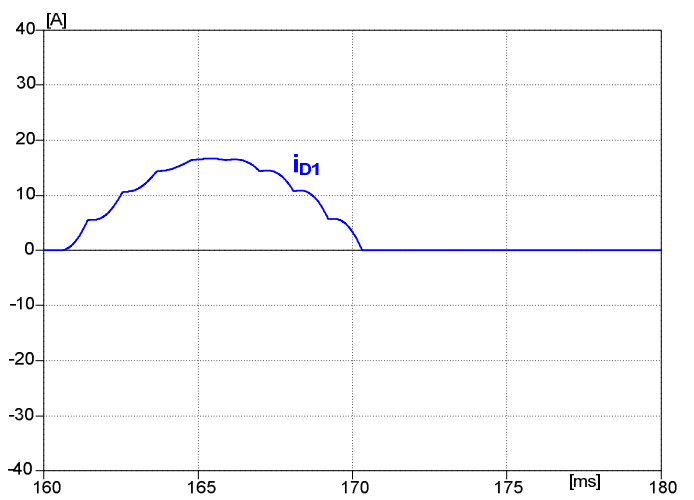

Fig. 11. Oscillogram of the diode D1 current in the bridge rectifier P2; the conduction angle is almost equal to $180^{\circ}$ simulation research at assumed rated load $20 \mathrm{~kW}$.

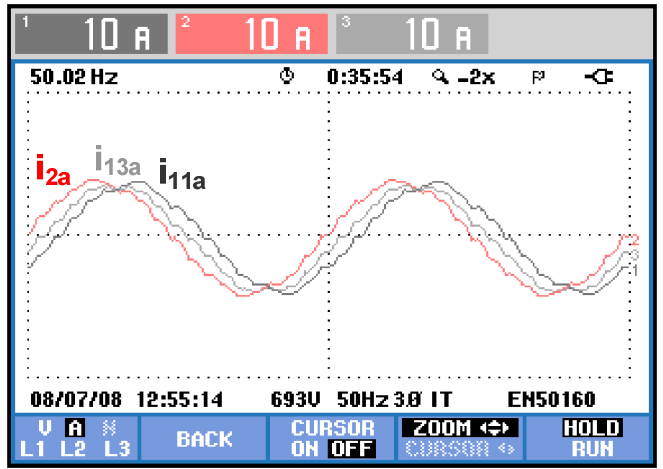

Fig. 12. Oscillograms of currents $i_{11 a}, i_{2 a}, i_{13 a}$ supplying bridge rectifiers. Real waveforms presenting shapes as well as shift angle between successive currents. Experimental tests atrated load.

\section{Conclusions}

The presented research work based on simulation and experimental tests proved a significant usefulness of 18 -pulse rectifier for supplying multilevel inverters. The paper presents the rectifier connected to the line by use of three-phase coupled reactors. The 18 -pulse rectifier consists of two classic bridge rectifiers and the reactors are connected and work in a special circuit arrangement described in this contribution. The application of such a solution makes that the diodes conduction angle in rectifiers achieves almost $180^{\circ}$. The additional internal inductance improves the shape of the supply current waveform. For the inductance $\mathrm{L}_{\mathrm{s}}=20 \mathrm{mH}$ and the assumed load of $20 \mathrm{~kW}$, the $\mathrm{THD}_{\mathrm{i}}$ value reaches a very low level. The converter system ensures considerable reduction of the distortion coefficient $\mathrm{THD}_{\mathrm{I}}$ of source supplying currents.

\section{References}

[1] J. Iwaszkiewicz, P. Bogusławski, A. Krahel, E. Łowiec, "Three-phase Voltage Outages Compensator with Cascaded 
Multilevel Converter", in Archives of Electrical Engineering, Vol. 61, No. 3, pp. 325-336.

[2] J. Iwaszkiewicz, L. Wolski, M. Perez Donsión, "A Case Study Control on High Power Compensator of the Power Grid Irregularities for Industrial Appliances", in International Conference on Renewable Energy and Power QualityICREPQ'13, Bilbao, 20-22 March 2013, Spain.

[3] J. Iwaszkiewicz, A. Muc, "A three phase 3-level inverter with reduced THD factor", in International Conference on Renewable Energy and Power QualityICREPQ'18, Salamanca, 21-23 March 2018, Spain.

[4] J. Iwaszkiewicz, A. Muc, P. Mysiak, "A 12-pulse rectifier using coupled reactors for supplying three-level inverters", ICREPQ'19, Santa Cruz,10-12 April, 2019, Spain.

[5] IEEE Std 1159-2009 (Revision of IEEE Std 1159-1995) IEEE Recommended Practice for Monitoring Electric Power Quality

[6] P. Mysiak, "Multipulse Diode Converters - Frequency Doma in Analysis of Operation of the Applied Coupled Three-Phase Reactor", in $6^{\text {th }}$ International Conference-Workshop, Compatibility And Power Electronics (CPE 2009), Badajoz, Spain, May 20-22, 2009.

[7] P. Mysiak, "Eighteen-pulse diode rectifier with three-phase coupled reactors", in Archives of Electrical Engineering, Vol. L, No 1, Warsaw, 2001.

[8] M. Depenbrock, C. Niermann, "A new 18-pulse rectifier circuit with line-side interphase transformer and nearly sinusoidal line currents", Conf. IAS, 1990.

[9] M. Depenbrock, C. Niermann, "Netzfreundliche Gleichrichterschaltung mit netzseitiger Saugdrossel (TDS) Teil II: Eigenschaften", in Etz Archiv Bd. 11 (1989) H.10, pp. 317-321. 